\title{
Prolonged QTc Interval, CTCAE
}

National Cancer Institute

\section{Source}

National Cancer Institute. Prolonged QT C Interval, CT CAE. NCI Thesaurus. Code C54937.

An adverse event characterized by an abnormally long interval between the start of the $\mathrm{Q}$ wave and the end of the T wave in the heart's electrical cycle, corrected for heart rate. 